\title{
Ultrasonographic evaluation of first trimester bleeding per vaginum
}

\author{
Neelam Gupta*, Meenakshi Samariya, Devika Choudhary, Kanti Yadav, Pushpa Kannoujiya
}

Department of Obstetrics and Gynaecology, JLN Medical College, Ajmer, Rajasthan, India

Received: 12 July 2016

Accepted: 05 August 2016

\section{*Correspondence:}

Dr. Neelam Gupta,

E-mail: ngneelam4922@yahoo.com

Copyright: (C) the author(s), publisher and licensee Medip Academy. This is an open-access article distributed under the terms of the Creative Commons Attribution Non-Commercial License, which permits unrestricted non-commercial use, distribution, and reproduction in any medium, provided the original work is properly cited.

\section{ABSTRACT}

Background: First trimester is a very crucial period of pregnancy having high risks of pregnancy losses. The objective of this study was to assess the accuracy of ultrasound in diagnosis of cause of first trimester bleeding per vaginum.

Methods: 200 women who attended the out-patient department with the complaint of bleeding per vagina in the first trimester pregnancy were taken for the study. Clinical assessment by pelvic examination was done and a provisional diagnosis was made. All necessary routine investigations were done followed by ultrasonographic scan of each patient. All the data was recorded in a proforma.

Results: Among these 200 cases, threatened abortion in 72 cases. It was the commonest cause for bleeding. There were 20 cases of ectopic pregnancy out of which 16 were correctly diagnosed. There were 16 cases of missed abortion. There were 8 cases of hydatidi form mole. There were 40 cases of incomplete abortion, 16 cases of inevitable abortion, 8 cases of an embryonic gestation and 20 cases of complete abortion. By this study it is concluded that the accuracy of USG in diagnosing the cause of first trimester bleeding per vaginum is $96 \%$.

Conclusions: Use of USG in diagnosis of cause of bleeding in first trimester can lead to accurate and early diagnosis and save the patients from unneeded interventions based on history and clinical examination.

Keywords: USG, Abortion, Ectopic pregnancy, Hydatidiform mole, Bleeding per vaginum

\section{INTRODUCTION}

First trimester is a very crucial period of pregnancy having high risks of pregnancy losses. Vaginal bleeding occurring in first trimester is a diagnostic challenge to the obstetrician. It causes physical and mental trauma to the patient and demands accurate diagnosis and proper management of the condition.

Estimate of the prevalence of first trimester bleeding per vaginum in early pregnancy is 7 to $24 \%$. Diagnosis thoroughly based on clinical backgrounds cannot fulfill the goal of correct diagnosis. Indeed many laboratory diagnostic tests cannot achieve the desired goal of early recognition.
Before the invention of USG, clinicians of that era used to diagnose the cause of vaginal bleeding solely based on clinical history and physical examination. Diagnosis was based on the history of amount of passing blood clots and foetal parts and grape like vesicles in case of hydatidiform mole.

This dilemma in the management of early trimester bleeding is solved by use of ultrasound examination which offers a reliable means of obtaining a clear picture of the pathology in first trimester bleeding. Since its introduction, technology has increased to such an extent that it is now possible to detect an intrauterine gestational sac as early as five weeks. Diagnosis of nature of the pregnancy (viable/non-viable) by ultrasound can avoid 
unnecessary complications and misdiagnosis in first trimester bleeding. ${ }^{1}$

Therefore this study was undertaken for differential diagnosis of cause of first trimester bleeding per vaginum by using ultrasound as a method and to find out the fallacy based on clinical examination. By this study the discrepancy between the clinical and ultrasonographic diagnosis is observed.

\section{METHODS}

In this study 200 women who attended the out-patient clinic in the department of obstetrics and gynaecology in our Hospital with the complaint of bleeding per vaginum in the first trimester pregnancy during August 2014 to July 2015 were included. Patient up to 12 weeks of gestational age were included and all non-pregnant cases were excluded.

Relevant clinical history, physical examination including pelvic examination was done in all patients and a provisional clinical diagnosis was made. In all cases routine investigations like hemoglobin blood grouping and $\mathrm{Rh}$-typing, urine pregnancy test by card were done. Then the patients were subjected to ultrasound examination. All the data was recorded in a proforma.

In USG examination following findings were noted like uterine size, presence of gestational sac, location of the gestational sac, size of gestational age compared to the period of amenorrhea, margins of the gestational sac either intact or created, presence or absence of foetal pole, crown rump length (CRL) of gestational sac, cardiac activity, foetal movements and presence of fluid in the cul-de-sac. More recent data, particularly when considering measurement variability, have suggested that a failed intrauterine pregnancy should be diagnosed only when cardiac activity is absent in an embryo $\geq 7 \mathrm{~mm}$, using trans-vaginal US. ${ }^{2}$ Bilateral adnexa were scanned to rule out ectopic gestation and other pathology.

All cases of threatened abortion were followed up regularly and expectantly.

\section{RESULTS}

This is a prospective study in which the value of USG for the diagnosis of cause of vaginal bleeding in the first trimester in 200 cases was assessed. Among these 200 cases, threatened abortion was seen as the commonest cause of bleeding. This was observed in 72 cases (36\%). During follow up, out of them, 48 cases had full term delivery $(66.67 \%), 8$ cases presented with complete abortion, 8 cases presented with incomplete abortion and 8 cases ended in missed abortion. There were $16(8 \%)$ cases of missed abortion in the present study. $8(4 \%)$ cases of an embryonic gestation were diagnosed based on USG, none of them were diagnosed clinically but ultrasound diagnosis was accurate in all cases and it was later confirmed by histopathological report. Incomplete abortion and complete abortion in 40 and 24 cases respectively.

There were 20 (10\%) cases of ectopic pregnancy. All 20 were tubal pregnancies out of which 16 cases were correctly diagnosed by USG rest 4 are diagnosed as complete abortion. 12 out of 20 patients underwent emergency laparotomy and unilateral salpingectomy. Rest cases were managed medically. There were 8 cases of hydatidi form mole. All cases were diagnosed correctly by USG. Molar pregnancy was diagnosed after evacuation and confirmed with histopathological examination.

Hence it is concluded that the accuracy of USG in diagnosing the cause of bleeding per vagina in the first trimester is $96 \%$. Due to high prediction rate, accurate assessment of first trimester bleeding can be done by ultrasound and management can be done accordingly.

\section{DISCUSSION}

Based on ultrasonographic diagnosis, out of 200 cases, there were 72 cases of threatened abortion, 16 cases of missed abortion, blighted ovum and incomplete abortion in 8 and 40 cases respectively. Complete abortion was seen in 24 cases, molar gestation and inevitable abortion was seen in 8 cases and 16 cases respectively. Ectopic pregnancy in 16 cases was found.

Table 1: Ultrasound findings Present study

\begin{tabular}{|llll|}
\hline $\begin{array}{l}\text { Ultrasound } \\
\text { findings }\end{array}$ & $\begin{array}{l}\text { Asha } \\
\text { Hanamshetty, } \\
\text { Sarita M. } \\
\text { Hattarki et al. }\end{array}{ }^{3}$ & $\begin{array}{l}\text { Deepti } \\
\text { Kurmi, } \\
\text { Vaishali R. } \\
\text { Jadhav et al. }\end{array}$ & $\begin{array}{l}\text { Present } \\
\text { study }\end{array}$ \\
\hline $\begin{array}{l}\text { Threatened } \\
\text { abortion }\end{array}$ & - & $50 \%$ & $36 \%$ \\
\hline $\begin{array}{l}\text { Missed } \\
\text { abortion }\end{array}$ & $20 \%$ & $11 \%$ & $8 \%$ \\
\hline $\begin{array}{l}\text { Blighted } \\
\text { ovum }\end{array}$ & $10.66 \%$ & $7 \%$ & $4 \%$ \\
\hline $\begin{array}{l}\text { Incomplete } \\
\text { abortion }\end{array}$ & - & $4 \%$ & $20 \%$ \\
\hline $\begin{array}{l}\text { Complete } \\
\text { abortion }\end{array}$ & - & $12 \%$ & $12 \%$ \\
\hline $\begin{array}{l}\text { Hydatidiform } \\
\text { mole }\end{array}$ & $4 \%$ & $1 \%$ & $4 \%$ \\
\hline $\begin{array}{l}\text { Ectopic } \\
\text { pregnancy }\end{array}$ & $5.33 \%$ & $3 \%$ & $8 \%$ \\
\hline $\begin{array}{l}\text { Inevitable } \\
\text { abortion }\end{array}$ & - & $1 \%$ & $8 \%$ \\
\hline
\end{tabular}

Age wise distribution shows $42 \%$ were in $21-25$ years age group, $28 \%$ were in 26-30 years age group, $4 \%$ were in 30-35 years of age and $26 \%$ was in 18- 20 years of age. There were 60 cases $(30 \%)$ of primigravida and 140 cases (70\%) of multigravida. 
Threatened abortion was diagnosed clinically in 104 cases but USG confirmed it only in 72 cases, giving a fallacious diagnosis in 32 cases. This is because all women with history of bleeding, having size of the uterus corresponding to the period of gestation were diagnosed as threatened abortions.

Table 2: Evaluation between clinical and USG based diagnosis.

\begin{tabular}{|llll|}
\hline Category & $\begin{array}{l}\text { Clinical } \\
\text { diagnosis }\end{array}$ & $\begin{array}{l}\text { Ultrasound } \\
\text { diagnosis }\end{array}$ & $\begin{array}{l}\text { Clinical } \\
\text { fallacy }\end{array}$ \\
\hline $\begin{array}{l}\text { Threatened } \\
\text { abortion }\end{array}$ & 104 & 72 & 32 \\
\hline Missed abortion & 4 & 16 & 12 \\
\hline $\begin{array}{l}\text { Inevitable } \\
\text { abortion }\end{array}$ & 8 & 16 & 8 \\
\hline $\begin{array}{l}\text { Incomplete } \\
\text { abortion }\end{array}$ & 64 & 40 & 24 \\
\hline $\begin{array}{l}\text { Molar } \\
\text { pregnancy }\end{array}$ & 4 & 8 & 4 \\
\hline $\begin{array}{l}\text { Ectopic } \\
\text { pregnancy }\end{array}$ & 16 & 16 & 0 \\
\hline
\end{tabular}

There were 40 cases of incomplete abortion. All patients were subjected to D and E and products are evacuated completely. There were 20 cases of ectopic pregnancies. All 20 were tubal pregnancies. USG was done in all the patients and accuracy was $96 \%$.

Table 3: comparison in accuracy of diagnosis of present study with other authors.

\begin{tabular}{|ll|}
\hline Authors & Diagnostic accuracy \\
\hline Asha et al & $38 \%$ \\
\hline D. Kumari & \\
\hline Mamatha et al $^{5}$ & $100 \%$ \\
\hline Nandish et al $^{6}$ & $100 \%$ \\
\hline Present study & $100 \%$ \\
\hline
\end{tabular}

This present study correlates well with Asha et al study. ${ }^{3}$ It shows that USG is a measure of accurate diagnosis for first trimester bleeding per vaginum.

\section{CONCLUSION}

Vaginal bleeding in the first trimester is a very common obstetric problem of pregnancy and it causes anxiety both to the patients and the obstetrician. Clinical history and pelvic examination are insufficient in assessing the cause and the outcome during follow up. Ultrasound is a noninvasive and easily available method of investigation to assess the patients with first trimester bleeding which is highly accurate in diagnosing the causes of bleeding and guides the clinician in choosing the appropriate line of management and prevents mismanagement of the cases. In the present study, 192 out of 200 cases were correctly diagnosed on ultrasound compared to 72 out of 200 cases on clinical diagnosis with a disparity of $64 \%$. We found very high incongruity between clinical diagnosis and ultrasonographic diagnosis. Correct management of cases depends on correct diagnosis and correct diagnosis is very difficult without ultrasound in cases of first trimester vaginal bleeding. ${ }^{7}$

Confirmation of abnormal and nonviable pregnancies by ultrasound facilitated early institution of appropriate treatment thereby lessening the physical and psychological morbidity for the patient. ${ }^{8}$

Funding: No funding sources

Conflict of interest: None declared

Ethical approval: Not required

\section{REFERENCES}

1. Yadav V, Santosh, Bharathi. Ultra sonographic evaluation and management of the first trimester bleeding. IOSR Journal of Dental and Medical Sciences. 2015;14(12):43-6.

2. Abdallah Y, Daemen A, Kirk E, Pexsters A, Naji O, Stalder C, et al. Limitations of current definitions of miscarriage using mean gestational sac diameter and crown-rump length measurements: a multicenter observational study. Ultrasound Obstet Gynecol. 2011;38(5):497-502.

3. Hanamshetty A, Hattarki SM. Ultra sound evaluation of first trimester bleeding. Journal of Evidence based Medicine and Healthcare. 2014;1(10):1356-61.

4. Kurmi D, Jadhav VR, Misri A, Mishra N, Prabhu S, Savani G. Role of pelvic sonography in first trimester bleeding. Journal of Evolution of Medical and Dental Sciences. 2015;4(49)8516-25.

5. Mamatha S, Sagar SG, Manoli N. Ultrasound evaluation of vaginal bleeding in first trimester of pregnancy: a comparative study with clinical examination. Int J Sci Stud. 2015;3(7):202-6.

6. Manoli N, Ramamurthy H. Role of ultrasound in first trimester bleeding - a study. Scholar's Press. 2013;2012.

7. Vidya C, Sanjaya S. Ultra sonographic evaluation of first trimestervaginal bleeding. Jarbs. 2011;3(2):60-2.

8. Padmaja P, Somashekar S. First trimester vaginal bleeding - evaluation by ultrasound. Indian journal of applied research. 2015;5:6.

Cite this article as: Gupta N, Samariya M,

Choudhary D, Yadav K, Kannoujiya P.

Ultrasonographic evaluation of first trimester

bleeding per vaginum. Int $\mathrm{J}$ Reprod Contracept

Obstet Gynecol 2016;5:3085-7. 